NASA Technical Memorandum 81517

\title{
PRACTICAL IMPLEMENTATION OF THE \\ DOUBLE LINEAR DAMAGE RULE AND \\ DAMAGE CURVE APPROACH FOR \\ TREATING CUMULATIVE FATIGUE DAMAGE
}

S. S. Manson

Case Western Reserve University

Cleveland, Ohio

and

G. R. Halford

Lew is Research Center

Cleveland, Ohio

April 1980

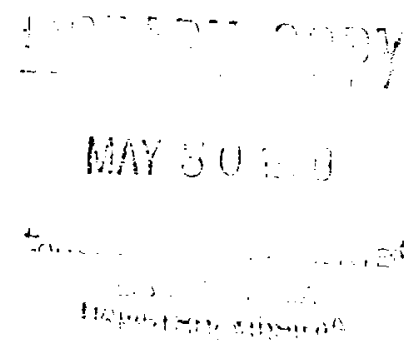



PRACTICAL IMPLEMENTATION OF THE DOUBLE LINEAR DAMAGE RULE AND DAMAGE CURVE APPROACH FOR TREATING CUMULATIVE FATIGUE DAMAGE

by

S.S. Manson, Professor of Mechanical and Aerospace Engineering Case Western Reserve University, Cleveland, $\mathrm{OH} 44106$

G.R. Haiford, NASA Lewis Research Center, Cleveland, OH 44135 ABSTRACT

Simple procedures are presented for treating cumulative fatigue damage under complex loading history using either the Damage Curve concept or the Double Linear Damage Rule. A single equation is provided for use with the Damage Curve approach; each loading event providing a fraction of damage until failure is presumed to occur when the damage sum becomes unity. For the Double Linear Damage Rule, analytical expressions are provided for determining the two phases of life. The procedure involves two steps, each similar to the conventional application of the commonly used Linear Damage Rule. When the sum of cycle ratios based on Phase I lives reaches unity, Phase I is presumed complete, and further loadings are summed as cycle ratios based on Phase II lives. When the Phase II sum reaches unity, failure is presumed to occur. No other physical properties or material constants than those normally used in a conventional Linear Damage Rule analysis are required for application of either of the two cumulative damage methods described. Illustrations and comparisons of both methods are discussed.

\section{INTRODUCTION}

Although the Linear Damage Rule (LDR) is commonly used in analyzing cumulative fatigue damage, it does not conform with the long established fact that order of loading significantly affects the summation of the cycle

$$
N 80-23684 \#
$$


ratios at failure. The non-conformity is particularly evident when high stress loadings are applied first, and low-stress loadings are subsequently applied until failure occurs. The sum of the observed cycle ratios is usually less than unity. Thus discrepancy is greater, the higher the ratio of the life at the low stress to the life at the high stress. On the other hand, if the low stress is applied first, followed by the high stress, the sum of the cycle ratios can be greater than unity.

It was early in the history of the study of cumulative fatigue damage that the loading order effect was observed, and many approaches have been formulated to explain it. One of the explanations offered is the need for two linear damage rules. Gover [1] first suggested such a need on the basis of separating the fatigue process into one of crack "initiation" and "propagation", hypothesizing that the first linear damage rule related to initiation, the second to propagation. By further hypothesizing that the fraction of life required to initiate a crack was itself a function of life - being small at short life, and high at long life - it became easy to explain the order effect. Grover's treatment was qualitative, however, and he provided no quantitative formulation for separating the total life into its two components.

Manson and co-workers followed Grover's lead in explaining the order effect $[2,3]$, as well as developing an independent approach [4]. In [2] an attempt was made to quantify the "double linear damage rule" by providing an explicit formula for partitioning the total life into its initiation and propagation phases. Further study [3] led, however, to some question as to whether it is even valid to regard the two stages involved as "initiation" and "propagation". For a given loading the end of the "initiation" stage may be at one cycle ratio when this loading is followed by loading at one stress level, but could be at a different cycle ratio if followed 
by loading at another stress level. In other words, "initiation" is a relative term, and depends on what is yet to come. Furthermore, careful examination of specimens loaded to a number of cycles, which, from previous tests, were known to be the effective "initiation" life, did not reveal the presence of measureable cracks. Thus, it could not be ascertained as to how large the crack must be to be regarded as "initiated". For this reason the terms "initiation" and "propagation" were abandoned and replaced by "Phase I" and "Phase II" to recognize that there was something different about the phases; although their physical interpretation was yet to be determined.

In [3], Manson, Freche and Ensign studied the Double Linear Damage RuTe (DLDR) behavior of a number of materials under two -block loading, and provided a formula for determining the "kneepoint" where the transition between the two phases occurred. Moderately good predictions could be made, but discrepancies were evident in some cases. It was concluded that for best practical results it was desirable actually to conduct the tests necessary to determine the kneepoint associated with the highest and lowest stress levels involved in a given application. The coordinates of the kneepoint then permitted the determination of two points on each curve of the two phases described by the DLDR, and it was suggested that the interpolated regions of the curves could be estimated by the investigator by sketching smooth curves through these points. No formulas were provided, however, thus making quantitative analysis difficult. 
Since the publication of [3] attention has been directed by the present authors toward the solution of the two important remaining problems required for the practical implementation of the DLDR; an analytical procedure for determining the kneepoint without need for exreriment, and the development of equations for expressing the Phase I and Phase II $1 \mathrm{i}$ fe curves over the entire range of interest in a given application. It is the purpose of this report to explain the reasoning used to attack these problems and to present the solutions.

\section{RATIONALE OF APPROACH}

Although the final cumulative damage equations are simple, the process leading to their development involved several steps. The following discussion of these steps may be used in maintaining a perspective of why they were introduced.

The first step is to establish a model for damage accumulation. It is recognized that the major manifestation of damage is crack growth. While the conventional treatment of fatigue involves tracking the growth of a single dominant crack, it is recognized that the early stages wherein such a dominant crack is developed involves many complicated processes such as dislocation agglomeration, subcell formation, multiple microscopic crack formation, and the independent growth of these cracks until they link and form the dominant crack. In order to account for these early processes, we make use of empirical information, established over a considerable period for many materials. Thus, we establish an "effective crack growth" equation which automatically accounts for the early processes without specifically defining or tracking them. This effective crack growth equation is then regarded as a model for damage accumulation. 
Once the damage accumulation equation is established, either of two procedures can be followed. One is the direct use of the equation to track damage as loading is changed. We refer to this approach as the Damage Curve Concept $(D C)$, which is already well-established from previous research (e.g., $[5,6])$. Whereas previous treatments used other functional forms of the damage curves, and parameters that required experimentation for each material, the method we have developed universalizes the parameters involved, and no experiments are necessary to implement the method.

Because the $D C$ concept results in rather complex numerical analysis, a second procedure is developed whereby the DLDR

provides the basic framework. Rather than regarding the two linear regions as related to "crack initiation" and "crack propagation", they are regarded as two "phases" that result when the damage curves are replaced by two linear segments. Thus, the two phases are defined by their mathematical rather than their physical implications, although the two are loosely related, as will be discussed later. Repiacing the DC procedure by the DLDR concept results in considerable simplification of the mathematics.

The advantage of regarding the DLDR as a consequence of the linearization of the damage curves rather than resulting from the separation of the total life into its "initiation" and "propagation" phases is that it avoids the confusion associated with the observation made in [3] that "initiation" at a life level depended not only upon that 1 ife but also the later life level at which the fatigue process is continued. The result, as already noted, was the introduction of the terminology Phase I and Phase II to replace "initiation" and "propagation". However, in [3] it was not clear how to calculate the dividing point; hence an experimental approach was required. 
A requirement for experimentation involves expense and is inconvenient when numerous exploratory calculations are required. Thus, a need has existed to determine the point of transition analytically. This goal has been accomplished in this report.

By linearizing the generalized damage curves, the point of intersection of the two resulting straight lines is used as the transition. It will be shown that this point depends on the ratio of the lowest and highest life levels, $N_{1} / N_{2}$, involved in the loading sequence to be analyzed. The analytical relation is determined not only from the linearized damage curves but from extensive experimental results obtained in previous investigations. Thus, the first step of an analysis is to determine from the loadings in a particular application the highest and lowest life levels involved, and then to determine from the formulas presented where the transition between Phase I and Phase II would be in a two-load-level test at the lowest life level and highest life level in the actual sequence being analyzed. That is, we determine how many cycles of the lowest life level should be applied before changing over to the high life level so that all the Phase I life is consumed by the low-life loading, and all the Phase II life is consumed by the subsequent high-life loading. The concept involved here is analogous to the method of Corten and Dolan [7] wherein they replaced the regular S-N curve by a new one with coordinates established at the extremes of the life levels involved in the sequence to be analyzed. In the present method, however, we seek to determine two curves - one for Phase I and another for Phase II - in the range of the life levels entering the practical problem to be studied. Since from the transition point (kneepoint) we know the number of cycles to complete 
Phase I for the lowest life level $N_{1}$, we can get the life level for Phase II by subtraction from $N_{1}$. Likewise, since we know the number of cycles to complete Phase II for the highest life level $\mathrm{N}_{2}$, we can also get the Phase I life for $\mathrm{N}_{2}$ by subtraction. Thus, knowing the lives at the kneepoint provides us with two points on both the Phase I and Phase II life curves. If, indeed, the loading involved only two levels, knowing the kneepoint would be all that is needed to analyze any combination of these loadings. The discrete values of Phase I and Phase II 1 ives at $N_{1}$ and $\mathrm{N}_{2}$ are sufficient. If we assume that other loading levels intermediate between the two will also be present, then it is necessary to draw a curve for the Phase I and Phase II lives as a function of the loading parameter (stress, strain, load, etc.). We accomplish this purpose by choosing for the Phase I life an expression involving two parameters, so that knowledge of two coordinates will establish the parameters. The shape of the Phase I curve is also chosen so that if it is extrapolated to very long lives it will asymptotically approach the basic life curve (total life, consisting of both Phase I and Phase II) at very high life levels. This characteristic derives from the knowledge that for very long lives crack initiation occurs at a very high fraction of the failure life; thus we carry over the analogy between "initiation" and Phase I to display this characteristic as well. Using this restriction, a simple analytical expression is obtained for the Phase I life, and the Phase II 7 ife is obtained by subtraction from total life.

Once the two life curves are known, the damage analysis proceeds just as with the LDR. However, it is performed in two steps. First 
the cycle ratios are based on the life values from the Phase I curve. When such cycle ratios add to unity, Phase $I$ is presumed to be complete. Then cycle ratios are based on the Phase II life curve. When the second sum reaches unity Phase II is complete and failure is assumed to occur.

Although the procedure is developed by considering the coordinates of the kneepoint in a loading sequence with high load first, the resulting Phase I and Phase II curves are usable for any order of loading, even a two-level test with low load first. This can easily be seen in the specific examples shown later in the report. In fact, the procedure could have been devised by considering a low-high load sequence, using the correlations discussed in the report; the resulting Phase I and Phase II curves would be the same. Thus, these curves are usable for any sequence of loadings between the extremes. However, some small effects associated with loading order can be expected, as will be discussed in the report.

In the following we shall develop both the DC and the DLDR concepts, and illustrate their application to some extensive experiments discussed in the literature.

\section{CRACK GROWTH MODEL}

In [8] we presented an equation for the number of cycles $N_{.003}$ required to develop a crack $.003 \mathrm{in.} \mathrm{deep} \mathrm{in} \mathrm{terms} \mathrm{of} \mathrm{the} \mathrm{life} \mathrm{to} \mathrm{failure} \mathrm{N}_{\mathrm{f}}$ of a $1 / 4 \mathrm{in}$. dia. test specimen

$$
N_{.003}=N_{f}-2.5 N_{f}^{2 / 3}
$$

In other reports $[9,10]$ the number of cycles required to propagate a crack to failure after it had penetrated $.013 \mathrm{in}$. was given as $4 \mathrm{~N}_{\mathrm{f}} 0.6$. Thus, 
the number of cycles to $\mathrm{N}_{.013}$ required to develop a crack .013 in. deep is

$$
N_{.013}=N_{f}-4 N_{f}^{0.6}
$$

Since in both these cases the formulas were empirical, their forms being arbitrarily chosen to fit certain experimental results, it is possible to choose other analytical forms, keeping the numerical values by the altered formula to provide reasonable consistency with the numerical values implied by Eqs. (1) and (2).

For purposes of further application to the cumulative fatigue problem the form pursued was

$$
a=a_{0}+\left(a_{f}-a_{0}\right)\left(N_{a} / N_{f}\right)^{B N_{f}^{\alpha}}
$$

In this formula $\mathrm{N}_{\mathrm{a}}$ is the applied cycles to reach a crack length of a, and $a_{0}$ the characteristic defect length of the material when $N_{a} / N_{f}=0$. The value of $a_{f}$ is the crack length at fracture when $N_{a} / N_{f}=1$. For a $1 / 4$ dia. specimen it might be expected that $a_{f}=0.25$, the full specimen depth. But, as pointed out in [2] the crack growth rate is so rapid near the fracture condition that almost any number close to 0.25 could be used. The value of $a_{f}=0.18$ was chosen in [2] on the basis of several considerations. The equation then reduces to

$$
a=a_{0}+\left(0.18-a_{0}\right)\left(N_{a} / N_{f}\right)^{B N_{f}^{\alpha}}
$$


To obtain consistency with Eqs. (1) and (2) we first neglected $a_{0}$, and recast Eq. (3a) by twice taking logarithms, resulting in

$$
\operatorname{Ln}\left[\frac{\operatorname{Ln}(a / 0.18)}{\operatorname{Ln}\left(N_{a} / N_{f}\right)}\right]=\operatorname{Ln} B+a \operatorname{Ln} N_{f}
$$

Thus, cloosing $a=.003$ and determining $N_{a}$ from Eq. (1) for various values of $N_{f}$, and then choosing $a=.013$ with $N_{a}$ determined from Eq. (2) we can plot

the parameter on the left side of Eq. (4) vs. Ln $N_{f}$, resulting in determination of $B=2 / 3$ and $\alpha=0.4$. The crack length equation becomes

$$
a=a_{0}+\left(0.18-a_{0}\right)\left(N_{a} / N_{f}\right)(2 / 3) N_{f}^{0.4}
$$

The numerical values predicted by Eq. (5) are quite close to those associated with eqs. (1) and (2) for the two crack lengths involved, assuming $a_{0}=0$. For other values of $a_{0}$, more appropriate values of $\alpha$ and $B$ could be found, but for the present purpose this subject is not pursued further since, as will later be seen, the only number of significance in the cumulative damage application is $\alpha=0.4$.

\section{DAMAGE CURVE ANALYSIS}

Although this report is mainly concerned with the DLDR we divert briefly to a discussion of damage curves because their use aids us in determining the coordinates of the kneepoint of the cycle ratio curve needed for the DLDR.

Cumulative fatigue damage analys is through the use of damage curves have been used by a number of investigators $[5,6]$ as reviewed by Kaechele [11]. Figure 1 shows the basis of the approach. The curves plot the accumulation 
of "damage" as a function of cycle ratio for various life values. The LDR would require that the curves be coincident for all life level, it is their separateness that produces the loading order effect. All curves start at the origin which represents the initial condition of the material where the damage state is zero, and terminate at failure $F$ where $D=1.0$.

The $D C$ concept is that damage accumulation proceeds along the curve associated with the life level at which a cycle ratio is applied. For example if a cycle ratio $n_{1} / N_{1}=n_{A} / N_{1}$ is first applied at the life level $N_{1}$, the damage will go from zero to $A$. If at this point a new loading level is introduced, the life of which is $\mathrm{N}_{2}$ and the damage curve for which is $O B F$ we first find the point $B$ at the same damage as $A$ (since no damage is added by simply preparing to apply cycles at the next load level). If $n_{2}$ cycles are then applied at the $\mathrm{N}_{2}$ life level, the point $C$ is located. as shown. Similarly, if $n_{3} / N_{3}$ is applied at the $N_{3}$ life level we locate the point $D$ at the same level as $C$, and increment $D E$ by the cycle ratio $n_{3} / N_{3}$, and so on for any arbitrary sequence of loading. When point $F$ is reached failure occurs.

The extent of the loading order effect is clearly shown in the figure. For example, in a two-level test at which the first load is applied at the low life level, say from 0 to $A$ followed by a loading at a higher life level, say from $B$ to $F$, the sum of the cycle ratios clearly omits the distance $A B$ and is therefore less than unity. However, if the high life cycle ratio is applied first along $O B$, followed by the low life cycle ratio along $A F$, it is clear that the cycle ratio associated with $A B$ is included twice, and therefore the summation of the cycle ratios is greater than unity. 
A7though the $D C$ concept has been used by various investigators, there have not been any specific numerical assignments for the damage curve equations. Power laws for $D$ such as $\left(n / N_{f}\right)^{\alpha}$ have been used, where $\alpha$ is a function of $N_{f}$, but specific functional forms for $\alpha$ in terms of the life values involved have not been proposed. For our analysis, we shall first derive equations based on the $D C$ concept, using as a quantitative model for damage the analog of the crack growth Eq. (5). Thus, if we assume

$$
D=\frac{1}{0.18}\left[a_{0}+\left(0.18-a_{0}\right)\left(n / N_{f}\right)(2 / 3) N_{f}^{0.4}\right]
$$

we have a damage curve law that has the value $D=1$ at $n / N_{f}=1$ for all values of $N_{f}$, and $D=a_{0} / 0.18$ is a small value for $n / N_{f}=0$.

Applying Eq. (6) in connection with the first increment of loading $n_{1} / N_{1}$ along $O A$ in Fig. 1 , we obtain the value of $D$ at $A$ and $B$

$$
D_{B}=D_{A}=\frac{1}{0.18}\left[a_{0}+\left(0.18-a_{0}\right)\left(n_{1} / N_{1}\right)^{(2 / 3) N_{1}^{0.4}}\right]
$$

Had we proceeded to point $B$ along path $O B$, the cycle ratio required would be $\mathrm{n}_{2}{ }^{\prime} / \mathrm{N}_{2}$ and the damage

$$
D_{B}=\frac{1}{0.18}\left[a_{0}+\left(0.18-a_{0}\right)\left(n_{2}{ }^{1} / N_{2}\right)(2 / 3) N_{2}^{0.4}\right]
$$


Thus, equating $D_{B}$ from Eq. (7) to $D_{B}$ from Eq. (8), we get

$$
n_{2}^{\prime} / N_{2}=\left(n_{1} / N_{1}\right)^{\left(N_{1} / N_{2}\right)^{0.4}}
$$

When the added $n_{2} / N_{2}$ cycle ratio is applied along $B C$, the total cycle ratio at point $C$ is

$$
n_{2}^{\prime} / N_{2}+n_{2} / N_{2}=\left(n_{1} / N_{1}\right)^{\left(N_{1} / N_{2}\right)^{0.4}}+n_{2} / N_{2}
$$

If we proceed in the same manner to find the total cycle ratio at point $E$ it becomes

$$
\left\{\left(n_{1} / N_{1}\right)^{\left(N_{1} / N_{2}\right)^{0.4}}+n_{2} / N_{2}\right\}^{\left(N_{2} / N_{3}\right)^{0.4}}+n_{3} / N_{3}
$$

If point $E$ coincided with point $F$, expression (11) would be set equal to unity, implying that failure occurs. In the more general case when $\mathrm{K}$ loadings are applied before failure occurs, the equation for $D C$ analysis becomes

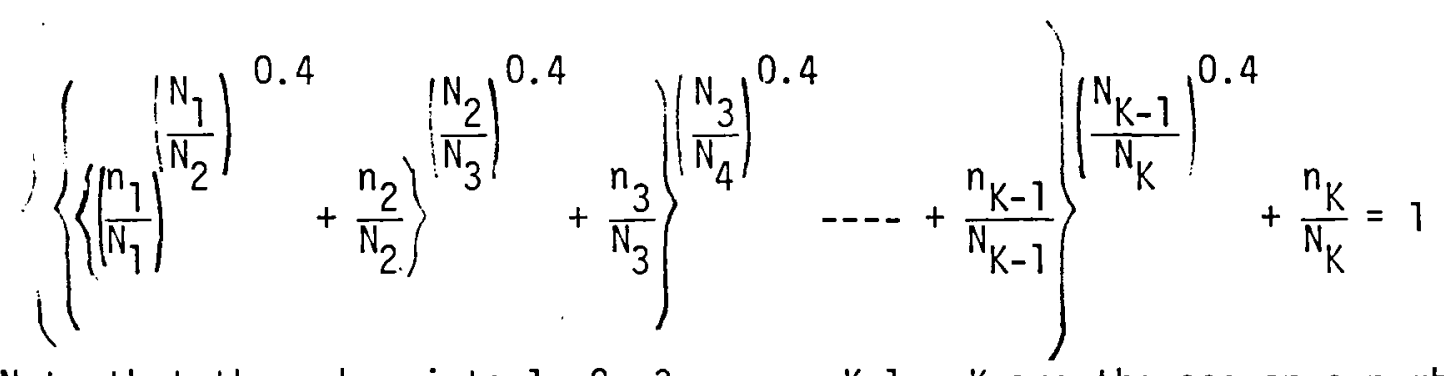

Note that the subscripts $1,2,3, \ldots, K-1, K$ are the sequence numbers of the loadings as they occur, and in general will not coincide with increasing life level as used in the example of Fig. 1. While Eq. (12) 
is very symmetrical, and its application is actually rather simple once the analyst becomes accustomed to its use, we will examine this method only cursorily in this report. Primarily, we shall make use of the specific equation for a two load level test in order to establish the kneepoint for use with the DLDR, as will be described later. Of particular interest in Eq. (12) is that the only constant that remains in the final equation is the exponent 0.4 ; al1 the others cancel in the derivation. In fact, even this constant is not critical. Examination of a series of other values in the range from 0.3 to 0.5 reveals the final results are not greatly altered compared to using the value 0.4 . Thus, for the continued discussion, such use as will be made of Eq. (12) will be based on the universalized value of 0.4 as the exponent with the reasonable assumption that even if this value differs somewhat among materials, the results will not significantly be affected.

\section{SELECTION OF EXTREME LIFE LEVELS}

As noted earlier the implementation of the DLDR will be accomplished by selecting the constants involved in the calculations using the highest and lowest life levels of interest in a particular application. If these life levels are used to establish a kneepoint of a double-linear curve that results when the loading consists of only these two stress levels, two points will be established on the Phase I and Phase II curves. The complete curves are established by imposing additional reasonable requirements. All other loadings will then be analyzed as interpolations, using the same Phase I/Phase II curves. The question arises as to which are the two life levels to be so used. The lowest life level is not difficult to identify. It is usually associated with the grand hysteresis loop of the complete loading spectrum, and involves the total range from extreme-to- 
extreme of loading. In many cases no mean stress will be present if sizeable plasticity is involved; if mean stress is present, however, its effect must be included to establish this lowest life, as will be discussed later.

It would seem reasonable to assume that the lowest life level $N_{\text {low }}$ used to construct the kneepoint should have a certain minimum damaging effect, say $0.1 \%$ when calculated on the basis of a preliminary analysis using the LDR. For loadings leading to lives less than 1000 cycles this criterion would recognize the presence of even one cycle as significant. Of course, any high strainrange loading, if it influences the mean stress of later lower loadings, must be considered in this respect regardless of whether or not it is used to establish the kneepoint.

The choice of the highest life of interest $N_{\text {high }}$ may present some difficulty. It should also be a life level for which some significant damage is present. For example, if a single cycle of loading at a condition that has a $10^{6}$ life is imposed, while a 11 other loadings involve lives less than $10^{5}$ cycles, it will be clear in the final analysis that this single cycle imposes relatively little damage. It may then be desirable to re-evaluate damage on the basis of the $10^{5}$ life as the highest life involved, giving emphasis to those loadings that were most significant in the actual problem analyzed. Experience is a valuable tool. However, it should be emphasized that even though some loadings may be neglected in establishing the kneepoint, their damaging effects may still be included in the analysis, by extrapolating the resulting Phase I and Phase II curves beyond the extremes associated with the life levels chosen for establishing the knee. Some further discussion of this subject will be provided later but study is needed to establish criteria for extreme loading conditions. 
ANALYTICAL REPLACEMENT OF DAMAGE INTERACTION BY - .0 STRAIGHT LINES When only two levels of loading are involved Eq. (12) becomes

$$
\left(n_{1} / N_{1}\right)^{\left(N_{1} / N_{2}\right)^{0.4}}+n_{2} / N_{2}=1 \text {, or } n_{2} / N_{2}=1-\left(n_{1} / N_{1}\right)^{\left(N_{1} / N_{2}\right)^{0.4}}
$$

If a plot is made of $n_{2} / N_{2}$ vs. $n_{1} / N_{1}$ a smooth continuous curve results passing through $(0,1)$ and $(1,0)$ at the extremities, as seen in Fig. 2 . The $D C$ concept is not based on the requirement of the representation of the results by two straight lines, and it is clear from the figure that no such straight lines result; the curves are continuous and of continuous slope. If, however, we wish to use these results as a basis for establishing an "effective" linear damage rule approximation, it would be necessary to replace the continuous curve by two straight Tines. To obtain the coordinates of the kneepoint, i.e. the intersection between these two straight lines, we made use of several observations and required criteria:

a) Since the portion of Eq. (13) involving $i_{1}$ and $i_{2}$ contains these terms within the ratio $\mathrm{N}_{1} / \mathrm{N}_{2}$, then the coordinates of anv effective kneepoint should also contain only the single parameter $\mathrm{N}_{1} / \mathrm{N}_{2}$. Herein lies the major difference between the present method and that described in [2]. If the process involve: is considered as "initiation" and "propagation", then the $n_{1} / N_{1}$ coordinate should depend only on $N_{1}$, since it is at $n_{1} / N_{1}$ that the crack "initiates". Once initiated, the crack is present for any level of $\mathrm{N}_{2}$ which is later used to propagate the crack. Similarly the vertical coordinate of the kneepoint should depend only on $\mathrm{N}_{2}$, since the cycle ratio to propagate the crack depends on the load level of the propagation 
period, and not the previous load level to initiate it. By choosing both coordinates as functions of $\mathrm{N}_{1} / \mathrm{N}_{2}$ we abandon the "initiation"/"propagation" mechanism, and replace it with a Phase I/Phase II description comprising the linearization of the damage curves of Fig. 2 .

b) The choice of kneepoint should be made with consideration for the numerous two-level tests that have already been conducted and interpreted according to the DLDR.

c) The single load level test must degenerate properly to the predictions of the two-load level tests when both load levels are equal. That is, in Fig. 2 the kneepoint must lie on the line joining $(0,1)$ to $(1,0)$ for $N_{1} / N_{2}=1$.

By first plotting the coordinates $\left(n_{1} / N_{1}\right)$ and $\left(n_{2} / N_{2}\right)$ of the kneepoint for two-load level experiments versus $N_{1} / N_{2}$ on logarithmic coordinates we observed that resulting approximate straight lines could be drawn having the same slope. Thus, we can represent the kneepoint coordinates by

$$
\left.\left.n_{1} / N_{1}\right]_{\text {knee }}=A\left(N_{1} / N_{2}\right)^{\beta} \quad ; \quad n_{2} / N_{2}\right]_{\text {knee }}=B\left(N_{1} / N_{2}\right)^{B}
$$

Therefore

$$
\left[n_{1} / N_{1}+n_{2} / N_{2}\right]_{\text {knee }}=(A+B)\left(N_{1} / N_{2}\right)^{B}
$$

But when $N_{1}=N_{2}=N$, we know according to condition (c) above that $n_{1}+n_{2}=N$ so that

$$
\left[\left(n_{1}+n_{2}\right) / N\right]=(N / N)=(A+B)(N / N)^{B} \text { resulting in } A+B=1
$$


A log-log plot of $\left[n_{1} / N_{1}+n_{2} / N_{2}\right]_{\text {knee }}$ vs. $N_{1} / N_{2}$ for data sets with $\mathrm{N}_{2} \neq \mathrm{N}_{1}$ should therefore result in a straight line through the origin yielding the slope $B$. Such a plot is shown in Fig. 3, from which $\beta=0.25$.

Fig. 4 shows the plot of $\log \left(n_{2} / N_{2}\right)_{\text {knee }}$ vs. $\log \left(N_{1} / N_{2}\right)$ which according to Eq. (14) should yield a straight line. Constructing this line to be of slope 0.25 we obtain a value of intercept $B=0.65$. Thus $A=0.35$. The kneepoint coordinates are

$$
\left.\left.n_{1} / N_{1}\right]_{\text {knee }}=0.35\left(N_{1} / N_{2}\right)^{0.25} ; \quad n_{2} / N_{2}\right]_{\text {knee }}=0.65\left(N_{1} / N_{2}\right)^{0.25}
$$

Eq. (17) applies only when the life, $N_{1}$, at the first loading level is shorter than the life, $\mathrm{N}_{2}$, at the second loading level and represents the relations of interest in establishing the Phase I/Phase II life curves. Implicitly, from these curves, the opposite loading order long life loading followed by short life loading - automatically produces the appropriate result that the sum of the cycle ratios is greater than unity when only two loading levels are applied. However, explicit relations can also be obtained for this case by noting the symmetry of the damage curves in Fig. 2 about the diagonal when $N_{2}<N_{1}$. The equations for this case can therefore easily be shown to be

$$
\left.\left.n_{1} / N_{1}\right]_{\text {upper knee }}=1-0.65\left(N_{1} / N_{2}\right)^{-0.25} ; n_{2} / N_{2}\right]_{\text {upper knee }}=1-0.35\left(N_{1} / N_{2}\right)^{-0.25}
$$


The effectiveness of Eqs. (17) and (18) in representing the kneepoints for two-load level experiments conducted on four different alloys is shown in Figs. 5 to 8 . The results for maraging $300 \mathrm{CVM}$ steel and SAE 4130 steel shown respectively in Figs. 5 and 6 are from [3] and previously unpublished NASA data. Results for Ti-6A]-4V from [12] are shown in Fig. 7 and for D.T.D. 683 aluminum [13] in Fig. 8. In each case the straight lines are drawn to the kneepoint determined from Eqs. (17) or (18) for the life levels used in the tests and shown in the figures. The dotted curves are the $D C$ representation of the test conditions, using Eq. (13). In Figs. 5-7 the plots are for $n_{2} / N_{2}$ vs. $n_{1} / N_{1}$, while for Fig. 8 the sum of $n_{1} / N_{1}$ and $n_{2} / N_{2}$ is plotted against $n_{1} / N_{1}$ since the data of [13] were presented in this form. Also of interest in Fig. 7 are several plots for $\mathrm{Ti}-6 \mathrm{Al}-4 \mathrm{~V}$ wherein a mean stress was maintained at the $\mathrm{N}_{2}$ life level. The plots show that the kneepoint formulas are equally effective for this case as well as for completely reversed loading, although more data are required to verify this conclusion more generally.

\section{EQUATIONS FOR THE TWO PHASES IN THE DLDR APPROACH}

The importance of Eqs. (17) and (18) does not lie in analyzing two-load level tests; such loadings do not occur very often in service. The use is primarily for determining the life curves for the two phases in the DLDR approach to damage accumulation for more complex loadings. 
The basic procedure for the DLDR is as follows: We assume that if the individual loadings within the block have lives from $\mathrm{N}_{10 \mathrm{w}}=\mathrm{N}_{1}$ to $\mathrm{N}_{\text {high }}=\mathrm{N}_{2}$, any combination of such loadings will follow the same DLDR, with the kneepoint being determined from Eq. (17). The horizontal coordinate $n_{1} / N_{1}$ provides the value of $n_{1}$, where $n_{1}$ is the Phase I life at the $N_{1}$ life level. The coordinate $n_{2} / N_{2}$ provides $n_{2}$ which is the Phase II life at the $\mathrm{N}_{2}$ life level, from which the Phase I life at $N_{2}$ becomes $\left(N_{2}-n_{2}\right)$. Knowing two points on the $N_{I}$ curve, we can then proceed by choosing the form

$$
\text { . } \quad N_{I}=N_{f} \exp \left(Z N_{f}^{\phi}\right)
$$

where $\mathrm{Z}$ and $\phi$ are constants. This form has the advantage of containing only two adjustable constants, which can be determined from knowledge of the coordinates of the kneepoint. It also has the feature that if $\phi$ is negative, $N_{I}$ approaches $N_{f}$ as $N_{f}$ becomes very large. Thus the $N_{I}$ curve does not intersect the $N_{f}$ curve, but approaches it asymptotically as $\mathrm{N}_{f}$ approaches infinity, which correlates with our knowledge that for very long lives crack initiation occurs at a very large fraction of total life (if we accept an analogy between Phase I and crack initiation, but not their equivalence).

To obtain two coordinates on the $N_{I}$ curve we apply the equation for the kneepoint, Eq. (17)

$$
N_{I, N_{1}}=N_{1}\left[n_{1} / N_{1}\right]_{\text {knee }}=0.35 N_{1}\left(N_{1} / N_{2}\right)^{0.25}
$$




$$
N_{I, N_{2}}=N_{2}\left[1-n_{2} / N_{2}\right]_{\text {knee }}=N_{2}\left[1-0.65\left(N_{1} / N_{2}\right)^{0.25}\right]
$$

Substituting into Eq. (19) allows the solution for $Z$ and $\phi$ as follows

$$
\begin{gathered}
\phi=\frac{1}{\operatorname{Ln}\left(\frac{N_{1}}{N_{2}}\right)} \operatorname{Ln}\left\{\frac{\operatorname{Ln}\left[0.35\left(N_{1} / N_{2}\right)^{0.25}\right]}{\operatorname{Ln}\left[1-0.65\left(N_{1} / N_{2}\right)^{0.25}\right]}\right\} \\
Z=\frac{\operatorname{Ln}\left[0.35\left(N_{1} / N_{2}\right)^{0.25}\right.}{N_{1}{ }^{\phi}}
\end{gathered}
$$

Thus Eq. (19) is the relation for $N_{I}$, using the values of $\phi$ and $Z$ from Eqs. (22) and (23).

The equation for $N_{I I}$ becomes

$$
N_{I I}=N_{f}-N_{I}=N_{f}\left[1-\exp \left(Z N_{f}^{\phi}\right)\right]
$$

As an illustration we consider a practical problem recently studied [12] involving a Ti-6Al-4V turbojet compressor disk at $77 \mathrm{C}(170 \mathrm{~F})$ wherein the loading cycle produced values of $N_{1}=2500$ cycles and $N_{2}=64,000$ cycles. Using Eqs. (22) and (23), we obtain $\phi=-.523$ and $Z=-111.2$, resulting in

$$
\begin{aligned}
& N_{I}=N_{f} \exp \left(-111.2 N_{f}^{-.523}\right) \\
& N_{I I}=N_{f}\left[1-\exp \left(-111.2 N_{f}^{-.523}\right)\right]
\end{aligned}
$$


Using the life curve as discussed in Appendix A, the results for this alloy are shown in Fig. 9. Appendix $A$, incidentally, illustrates an inversion procedure [14] which conveniently provides a closed form solution for $\mathrm{N}_{f}$ when the basic life relation provided consists of an expression for strainrange in terms of life. APPLICATION OF THE $N_{I} / N_{\text {II }}$ LIFE CURVES

Once the two life curves have been constructed, their use is analogous to the conventional linear damage rule. Cycle ratios are based on the Phase I life curve until the summation is unity; then cycle ratios are based on the Phase II life curve until again the sum is unity, at which time the region which is being analyzed is considered failed. If the life values used in the analysis are based on complete fracture of conventional ( $1 / 4$ inch diameter) specimens in uniaxial loading, the type of failure implied in the analysis is the development of a large crack - of the order of $1 / 8$ to $1 / 4 \mathrm{in.}$. If baseline life values involve smaller size cracks (obtained either experimentally, or calculated as approximations using Eq. (5)) then failure can be defined as the development of other sizes of crack. In the following discussion we shall use only life data involving complete failure, leaving other refinements to later study. As an example of the application of the method, we refer to a recent study [12] of the Ti-6Al-4V compressor disk of a small gas-turbine engine. This disk contained a bolt hole which was analyzed as shown in Table I. A series of events for which strainranges and mean stresses were analytically determined, are listed in columns (2) and (3). The number of cycles of each event which occurred per loading block (mission) is listed in Column (4). Column (5) lists the cycles to failure for each 
condition. Here the spline point inversion formula (Appendix A) was used, taking account of mean stress as outlined in Appendix $B$. Once $N_{f}$ is known for each condition the values of $N_{I}$ and $N_{\text {II }}$ can be determined from Eqs. (25) and (26). These values are listed in Columns (6) and (7).

To continue with the analysis is very simple. We sum cycle ratios based on lives of the Phase I process, as listed in Column (8). Since the sum of the cycle ratios based on Phase I loading is .0126 per block, the number of blocks required to complete Phase I is $1 / .0126=79$ blocks. Thus, after the first 79 blocks, damage is calculated according to cycle ratios based on Phase II loading, as shown in Column 9. Since the summation of cycle ratios based on Phase II loading is .005 per block, it requires $1 / .005=200$ blocks to complete this phase. Thus the total number of blocks is $70+200=$ 270 blocks.

This calculation was checked by subjecting specimens to the block loading history. In 220 blocks, cracks of about .015 to .030 inch developed. Since the calculations are based on complete fracture of $1 / 4$ in. dia. specimens, they naturally predict "failure" after a larger number of blocks, so the agreement must be regarded as very good (We are currently studying the question of modifying the value of $\mathrm{N}_{f}$ to use life to a particular size of crack, rather than complete rupture of test specimens, but since such data are more scarce than fracture data, our decisions are not yet firm). By comparision, the LDR for this problem predicts 306 blocks, which also is reasonably accurate in this case. The reason for this result is that there are relatively few cycles in each block of the loadings that produce small damage per cycle; thus these loadings produce a relatively 
small amount of the total damage. Increasing their damaging effect by interaction with the high amplitude loadings does not have the dramatic reduction effect on life that it does at the knee of a two-level test when the actual number of $\mathrm{N}_{2}$ cycles is very large relative to the $N_{1}$ cycles. In other cases, - for example, during low amplitude vibration following high amplitude loading, - the life reduction predicted by the DLDR would be much greater compared to the LDR.

\section{DISCUSSION}

That Eq. (17) is satisfactory for determining the coordinates of the kneepoint is amply demonstrated by Figs. 5-8. Other tests described in the references from which these figures were drawn provide additional verification, but are omitted here for brevity. Thus, it can be concluded that these formulas are adequate for representing two-level fatigue tests. However, the usefulness of the approach must be judged on the basis of whether more generalized loading sequences can be properly analyzed. Unfortunately the test programs for which data are available were not designed to test critically the difference between the two methods. In the program results to be discussed, the computed lives by the two methods differed only moderately. Nevertheless, they provide a useful framework for discussion.

The Three-Level Test Program of Webber \& Levy

In [13] Webber and Levy describe a very extensive fatigue test program on an aluminum alloy. Their main interest was to study data scatter in cumulative fatigue, so many tests were conducted at three stress levels, both singly and in sequences involving two stress levels, or all three. Statistical analysis of their data 
provided information on fatigue at any chosen level of probability of failure. For brevity only baseline fatigue properties at each stress level, and experimental results for multiple-stress tests, will be shown for the $50 \%$ failure probability of many duplicate tests, thereby permitting data scatter to be ignored.

The main results of the analysis are summarized in Table II. As noted, the three life levels involved were $51,900,414,140$ and 13,800,000 cycles. The two-stress level tests have already been summarized in Fig. 8. The results shown in Table II refer only to three-level tests, each duplicated 15 times. Each of the nine three-lever tests consisted of repetitive blocks of 9500 cycles within which loadings occurred at all three stress levels. The percentages of the loadings at each stress level are shown in Columns 2, 3, and 4. Thus, for example, Test 1 consisted of 95 cycles ( $1 \%$ of 9500) applied at the stress which alone yielded a life of 51,900 cycles, 5985 cycles at the stress for 414,1400 life level and 3420 cycles at the stress which lasted $13,800,000$ cycles when applied alone. The observed average (assuming a log-normal distribution) cyclic life for each set of loadings is listed in Column 5. Analysis by the LDR resulted in the cyclic life shown in Column 6. For the DLDR two calculations were made, one using $N_{1}=51,900$ and $N_{2}=13,800,000$ for the determinations of the kneepoint and the other using $N_{1}=51,900$ and $N_{2}=414,140$.

The damage of the cycles at the $13,800,000$ life level was then included by extrapolating the Phase I/Phase II life curves beyond those used to establish the kneepoint. The results for both calculations are shown in Columns 7 and 8 . Damage Curve analyses were also made according to Eq. (12), using the two exponents, 0.40 and 0.33 , as shown in Columns 9 and 10. Normalization of the calculations of Column 
6,7 , and 9 relative to the experimentally determined lives are shown in Columns 11 to 13.

Features of the Methods as Revealed by Analysis of Experimental Programs

We can now use results of Tables I and II as a framework around which to comment on certain features of the methods.

Treatment of mean stress. In evaluating the currently formulated DLDR we note that the input required is identical to that ordinarity required for any cumulative damage analysis; no additional data whatever are required. By expressing $N_{I}$ and $N_{I I}$ in terms of $N_{f}$ using Eqs. (19) and (24) we can account for mean stress as easily as not. When mean stress is present, $N_{f}$ is calculated according to any of several conventional methods which take account of the mean stress, and the $N_{I}$ and $N_{I I}$ values for this condition involving mean stress are determined as the intersections of the $N_{I}$ and $N_{I I}$ curves along the horizontal passing through the associated value of $\mathrm{N}_{f}$. One way of accounting for mean stress is discussed in [12], and illustrated in Appendix B.

The manner in which the transition is made from one stress level to another can be very important in relation to mean stresses developed. Minor nuances of detail can lead to different mean stresses, particularly when load levels in the high cycle fatigue range are mixed with low cycle fatigue loading. This subject is discussed in [12]. But it is important to recognize that an appropriate hysteresis loop anaiysis is required before a cumulative fatigue damage analysis can be undertaken.

Comparision of Double Linear Damage Rule with Linear Damage Rule. As can be seen by comparing Columns 5, 6, and 7 of Table II the DLDR 
generaliy produces better life predictions than the LDR. On average the DLDR estimates life for this service approximately $12 \%$ high (Column 12) while the LDR provides estimates $37 \%$ too high. In general, it can be expected that the DLDR will provide lower estimates of 1 ife because it allows for the damaging effects of high loadings on the life at subsequently applied lower loadings. Unusual cases involving only progressively increasing loading may, however, result in longer lives according to the DLDR than LDR, as suggested by Eq. (18) and illustrated in Fig. 5 by the test involving $N_{1}=584,750$ and $N_{2}=990$ cycles. The degree of difference resulting from calculations by the two methods depends, however, on the relative cycle ratios involved in the loading. As can be seen in Figs. 5 and 6 , large differences exist if the cycle ratios involved are near the kneepoint, in some cases by as much as a factor of 5 or more. However, if the conditions involved are such that $n_{1} / N_{1}$ or $n_{2} / N_{2}$ are close to unity, the other cycle ratio is nearly the same by the two methods. In other words, if nearly all the damage is done by one of the loadings, the contribution of the other loadings is small regardless of which method of calculation is used. This, in fact, is illustrated by both the experimental programs of Tables I and II. For the test program of Table II, in each case the cycle fractions associated with the $13,800,000$ loading is very small, and the calculated damage contributed by this loading is relatively small. Thus, these tests are basically two-step loading tests for purposes of cumulative fatigue damage analysis. The combinations of loading are such that the operating condition of the 414,140 cycle loading is dominant and it combines with an $n_{1} / N_{1}$ loading which is remote from the kneepoint. 
Thus, neither test program is designed to accentuate possible differences that can be calculated to occur according to the two methods. But sufficient differences can be seen in both cases to demonstrate that the DLDR is generally more accurate that the LDR.

A significant implication of the DLDR relative to the LDR is that high loadings can drastically lower resistance to later lower loadings. This can explain why "endurance limits" can be so greatly lowered in service applications involving some high loadings. It also suggests that vibrations of low amplitude involving large numbers of cycles when superimposed on large amplitude loadings can be very damaging even though their presence might be adjudged innocuous according to the LDR.

Comparision of Double Linear Damge Rule with Damage Curve approach. The DLDR approach is intended as a simplification of the Damage Curve concept, and predictions by the two methods will generally be reasonably consistent. This is shown in Figs. 5 to 8 for the two-level tests, and by a comparison of Columns 9 and 10 with Columns 7 and 8 in Table II. Whereas programming Eq. (12) for Damage Curve analysis can be accomplished easily on a computer, or even hand calculator when only a few loadings are present, it can become cumbersome when numerous loadings, such as those of Table I, are involved. Since the results are usually quite similar by the two methods, the DLDR may be regarded as preferable.

It should also be noted that whereas the Damage Curve method recognizes every change of loading order as significant in the calculation procedure (whether or not numerically significant in result), the DLDR does not place significance on loading order 
within each of the Phases. Thus, once the transition from Phase I and Phase II has been established, rearranging the loadings within Phase I or Phase II in orders other than as they actually occur does not alter the result of the life calculations. For example, in Test 1 of Table II DLDR calculations show that the transition from Phase I to Phase II occurs after 17.3 blocks of 9500 cycles, and Phase II is completed after the subsequent 36.2 blocks. Thus, in Phase I there are 1644 cycles of the 51,900 life level, 103,540 cycles of the 414,140 1ife, and 59,166 cycles of the $13,800,000$ life. In reality they occur in regular alternations. However, suppose we applied all the 1644 cycles of the 51,900 cycle life first, then all the 103,540 cycles of the 414,0001 ife, followed by the 59,166 cycles of the $13,800,000$ life. According to the DLDR the life would be the same since all the loadings within Phase I are the same, and Phase I lives are the same, and a linear damage rule is applied within this loading period. Does it not, actually make a difference? As an indication of what to expect we made a calculation in which all the Phase I and Phase II loadings were applied in decreasing load sequence, and another calculation in which they were applied in increasing load sequence. By the DLDR the results were, of course, unaffected, but by the Damage Curve approach differences were obtained.

In the decreasing load sequence, failure, according to the Damage Curve approach, would occur before all the loadings could be applied, and we would lose 30,970 cycles of the 414,140 loading in Phase II and 123,894 of the $13,800,000$ loading. Thus the loss is $30,970 / 41,140+$ $123,894 / 13,800,000=8.4 \%$ of the 1 ife fraction calculation by the DLDR. However, if the loadings are applied in decreasing life sequence, failure would not occur when the loadings allowed by the 
DLDR had been imposed. Additional life would be possible, the magnitude depending on whch stress level was used to complete the test. If the 51,900 life level were used, the remaining life would be 11,700 cycles, or $22.6 \%$ of this life level. If the 414,1401 ife level were used, the remaining life would be 43,720 or $10.5 \%$ of the 1 ife level. However, if the $13,800,000$ life level were used the remaining 1 ife would be 373,500 cycles, or $2.7 \%$. Thus, although the two methods indicate a difference in result, the effect is not very large. In service, interspersing of loadings is the more common occurrence, making the two methods agree more closely. But the subject should be studied further to gain insight as to what actually does happen, and to evaluate the relative accuracy and desireability of the two methods.

Choice of life levels for determination of kneepoint. The two life levels used to establish the kneepoint will generally be the highest and lowest life levels significantly involved in the loading history. In this way the Phase I and Phase II life curves are established over the complete loading history involved. However, ambiguities may develop as to whether the existence of relatively few cycles of high cycle loading qualifies that high life for use as the $\mathrm{N}_{2}$ for the entire loading sequence. To gain some insight into this question the calculations shown in Column 8 of Table II were performed. In these calculations the $\mathrm{N}_{3}=13,800,000$ cycles were ignored in establishing the kneepoint. $N_{1}$ was taken as 51,900 and $N_{2}=414,140$ to establish the Phase I/Phase II life values. However, these curves were extrapolated to determine the Phase I and Phase II lives at 13,800,000 cycles to failure, so that the damage due to this loading could be 
included. Column 8 of Table II shows that in most cases the results differed little from those of Column 7 wherein the highest life of $13,800,000$ cycles was actually used to establish the kneepoint. For test 6 , however, wherein the largest percent (81\%) of the block was at the 13,800,000 1ife level, an $11 \%$ difference in 1ife prediction occurred, but for such a loading sequence ambiguity would not normally arise in the choice of $\mathrm{N}_{2}$ because the $13,800,000$ cycle loading occurred for $3 \%$ of life during the loading history. Thus it can be concluded that when ambiguity occurs the high cycle loading can safely be ignored in establishing the kneepoint. But there is no reason to omit its damaging effect. By extrapolating the Phase I and Phase II life curves to the long life required, the damage can be included. Since the two life curves are tied to the $N_{f}$ curve by the wellconditioned Eq. (19), there is little chance that extrapolations will diverge far regardless of any reasonable choice of $\mathrm{N}_{2}$ in establishing the kneepoint.

Physical significance of the two phases. One of the major differences between the DLDR approach described in this report and that proposed in [2] and [3], is the abandonment of the terms "initiation" and "propagation" as the physical description of the two phases. When these descriptors are used the implication has to be that $n_{1} / N_{7}$ at the kneepoint must be a function only of $N_{1}$, and $n_{2} / N_{2}$ at this point a function onty of $N_{2}$. Figure 10 shows that the values of $n_{1} / N_{1}$ at the kneepoints for various tests in [2] and [4] do not correlate with $N_{1}$. Furthermore, if the crack lengths at the kneepoint are calculated from Eq. (5) (letting $a_{0}=0$ ), the values obtained for the tests conducted are so small as to be undetectable under normal circumstances. 
The kneepoints for most of the tests were at values of $n_{1} / N_{1}$ less than 0.2 or 0.3 , and the calculations indicate that detectable cracks of the order of .003 in. require cycle ratios $n_{1} / N_{1}$ greater than 0.8 to 0.9 , thus explaining why our early attempts to detect cracks at the kneepoint were unsuccessful. Thus, treating the DLDR as a process of initiation, followed by a propagation phase amenable to Linear Elastic Fracture Mechanics (LEFM) would involve applying LEFM to extremely small cracks, which is questionable.

Our approach of determining the coordinates of the kneepoint as a function of $N_{1} / N_{2}$ not only produces better correlation with experiment, but may have physical significance in relation to the type of damage involved and why the perception of the end of Phase I at the $\mathrm{N}_{1}$ life depends on $\mathrm{N}_{2}$. For example, we can assume that the early stages of fatigue consist of the development of damage sites associated with local plastic deformation. In Phase I these sites are discrete and separated from each other. Phase II produces linking and the development of a dominant crack. Thus, how the two life level loadings interact depends on how the second loading contributes to the transition from one mode of damage accumulation to the other. For this reason both loading levels are involved in the transition. This view is consistent with that expressed in [7]. More study is obviously needed to clarify the physical picture, but it is fortunate that the engineering treatment presented does not require a detailed knowledge of the physics. The formulas provided in this report permit engineering calculations even though the full understanding of the physics lie ahead. 
SUMMARY AND CONCLUDING REMARKS

Although a rather detailed discussion has been provided to explain the rationale for the DLDR approach the practical procedure is extremely simple:

a) Choose the lowest and highest life levels $N_{1}$ and $N_{2}$ involved in the loading sequence of interest, the choice not being critical. From these two life levels, and using Eqs. (19) and (24), calculate the life curves for Phase I and Phase II.

b) Analyze loadings just as would be done in conventional Linear Damage Rüe analysis, except do it in two stages. Instead of using the $N_{f}$ curve to establish cycle ratios, use the $N_{I}$ curve and add cycle ratios in the conventional manner until the summation reaches unity; Phase I is now complete. Then for continued loadings, sum cycle ratios using the $N_{I I}$ life curves; when these ratios sum to unity, Phase II is complete, and the part is considered "failed".

Thus, application of the DLDR requires no input information other than that required for a conventional Linear Damage analysis. Its main purpose is to account for a loading order effect known to occur with smooth specimens, and particularly to account for damaging effects of high loadings followed by low ones. The method does not pre-empt need for detailed analysis of hysteresis loops to establish strainranges and mean stresses for each event, which is also basically required when a LDR analysis is made.

Although a number of practical cases have been studied by the DLDR, experience is still limited. In general it can be expected that when high and low amplitude loadings are interspersed, predictions made by this method will be more conservative and accurate than those made by a Linear Damage Rule, which is desirable to promote 
safety. However, more study is needed to establish its true validity and value. More study is also needed to obtain a good perspective of its merits relative to the Damage Curve approach which in concept can be applied easily, although requiring laborious analysis for histories involving numerous events.

\section{ACKNOWLEDGEMENT}

The authors are grateful to U. Muralidharan, a graduate student at Case Western Reserve University, and to J.F. Saltsman, a scientist at NASA's Lewis Research Center, for numerous calculations performed by them, only some of which are contained in this report. Appreciation is also extended to Frieda Mosby of Case Western Reserve University for typing the manuscript. The research described was made possible, in part, by a Grant to CWRU by Lewis Research Center and by a contract between CWRU and the Nuclear Regulatory Commission. 


\section{APPENDIX A - ILLUSTRATION OF THE LIFE INVERSION PROCEDURE}

The inversion procedure is described in detail in [14]. Basically the life relation is given in the form

$$
\frac{\Delta \varepsilon}{2}=\varepsilon_{f}^{\prime}\left(2 N_{f}\right)^{C}+\frac{\sigma_{f}^{\prime}}{E}\left(2 N_{f}\right)^{b}
$$

To illustrate the procedure we refer to a recent study [12] on $\mathrm{Ti}-6 \mathrm{Al}-4 \mathrm{~V}$ at $170 \mathrm{~F}$ for which the equation is

$$
\frac{\Delta \varepsilon}{2}=2.852\left(2 \mathrm{~N}_{f}\right)^{-.9034}+0.01987\left(2 \mathrm{~N}_{f}\right)^{-.1229}
$$

In the spline point approach to the inversion procedure we first determine the transition strainrange and life, which in this case are $\Delta \varepsilon_{T}=2 \varepsilon_{f}^{\prime b /(b-c)}\left(\sigma_{f}^{\prime} / E\right)^{c /(c-b)}=0.0181$

$$
\text { where } E=112 \times 10^{3} \mathrm{MPa}\left(16.27 \times 10^{3} \mathrm{ksi}\right)
$$

$N_{T}=\left[1 / 2 E \varepsilon_{f}^{\prime} / \sigma_{f}^{\prime}\right]^{1 /(b-c)}=291$ cycles

We then calculate three constants

$$
\begin{aligned}
& \delta=\frac{0.78}{c}(c / b)^{0.36}=1.7704 \\
& \alpha=-0.17-0.52 \operatorname{Ln}(c / b)=-1.2071 \\
& \beta=0.5(c / b)-0.3=2.2743
\end{aligned}
$$

The inverted life relations become

$$
\begin{aligned}
N_{f} & =N_{T}\left(\Delta \varepsilon / \Delta \varepsilon_{T}\right)^{1 / c} \exp \left[\delta\left(\Delta \varepsilon / \Delta \varepsilon_{T}\right)^{\alpha}\right] \text { for } \Delta \varepsilon>\Delta \varepsilon_{T} \\
& =3.43 \Delta \varepsilon^{-1.107} \exp \left(.01396 \Delta \varepsilon^{-1.2071}\right) \text { for } \Delta \varepsilon>0181
\end{aligned}
$$


and

$$
\begin{array}{rlr}
N_{f} & =N_{T}\left(\Delta \varepsilon / \Delta \varepsilon_{T}\right)^{1 / b} \exp \delta\left(\Delta \varepsilon / \Delta \varepsilon_{T}\right)^{\beta}, \text { for } \Delta \varepsilon<\Delta \varepsilon_{T} \quad(A-10) \\
& =1.953 \times 10^{-12} \Delta \varepsilon^{-8.134} \exp \left(1.34 \times 10^{6} \Delta \varepsilon^{3.3742}\right) \text { for } \Delta \varepsilon<.0181 \quad(A-11)
\end{array}
$$

The agreement in 1 ife representation by Eqs. (A-9) and $(A-11)$ compared to representation by $E q .(A-2)$ is extremely close $[12,14]$. 


\section{APPENDIX B - MEAN STRESS EFFECTS}

The life relation such as Eq. (A-1) is valid for completely reversed strains without presence of mean stress. In the more general case when mean stress $\sigma_{0}$ is present the approximate equation is in the form

$$
\frac{\Delta \varepsilon}{2}=\varepsilon_{f}^{\prime}\left(2 N_{f}\right)^{c}+\frac{\sigma_{f}^{\prime}-k \sigma_{0}}{E}\left(2 N_{f}\right)^{b}
$$

where $k$ is an empirical constant [14] which should be determined experimentally. Since its introduction by Morrow (with $k=1$ ) [15], Eq. (B-1) has been used with considerable success in the long-life nominally elastic region. It has in fact been extended to the plastic regime by a number of investigators, e.g. Landgraf [16] and Manson [14]. Under elastic conditions the plastic strainrange is negligible, and its relation to the elastic strainrange is of little practical significance. However, at larger strainranges, wherein the plastic strainrange is an appreciable part of the total, it is important that the relationship between the elastic and plastic strainrange be maintained so as to imply a reasonable cyclic stress-strain curve in the presence of mean stress. Since Eq. (B-1) implies large differences in the cyclic stress-strain curves, depending on whether tensile or compressive mean stress is present, it is desirable to reconsider the appropriateness of retaining the same plastic line in the presence of mean stress, which is implied by Eq. (B-1).

Consider two cases: in the first tensile mean stress is present; in the second the mean stress is equal in magnitude, but compressive. If an alternating strainrange is applied in both cases, it would be expected that the associated stressranges would be equal, since the individual stresses in the tension case and compression case would be approximately equal but of opposite sign. In other words, the cyclic stress-strain curves should be nearly the same for tensile or compressive mean stress. One way of leaving the cyclic stressstrain curve unaltered by the presence of mean stress is to assume that 
the transition strainrange is unaffected by mean stress. Then the elastic line would be shifted according to Morrow's model, and the plastic lines would also shift to retain the same transition strainrange. When the transition strainrange is the same, the ratio of elastic strainrange to plastic strainrange is dependent only on strainrange; thus the cyclic stress-strain curve is unchanged by presence of any mean stress. It is possible, however, that, in a second case, mean stress does alter the cyclic stress-strain relation. In order to retain symmetry between the curves for both tensile and compressive stresses, the assumption should be made, therefore, that the transition strainrange depends only on the absolute value of mean stress, not its sign. Then, the relation between elastic and plastic strainrange will still depend only on strainrange, and the cyclic stress strain curves will be the same for equal values of both tension and compression, although different from the basic cyclic stress-strain curve for zero mean stress.

In order to generalize the possible behavior, we can assume that in the presence of mean stress the transition strainrange changes from $\Delta \varepsilon_{T}$ (at zero mean stress) to $k^{\prime} \Delta \varepsilon_{T}$ with mean stress, where $k^{\prime}$ depends only on absolute value of mean stress. Then, since the transition life must 1 ie on the elastic line, the relation to be satisfied is

$$
\frac{k^{\prime} \Delta \varepsilon}{2}=\frac{\sigma_{f}^{\prime}-k \sigma_{0}}{E}\left(2 N_{T}^{\prime}\right)^{b}
$$

where

$N_{T}^{\prime}$ is the corresponding transition life in the presence of mean stress, and the algebraic sign of $\sigma_{0}$ (positive for tension, negative for compression) governs the difference in associated $N_{T}^{\prime}$ for the two cases. Thus, solving for $N_{T}^{\prime}$ from Eq. $(B-2)$, and substituting into the general life relation from [14], 


$$
\frac{\Delta \varepsilon}{\Delta \varepsilon_{T}}=\left(\frac{N_{f}}{N_{T}}\right)^{b}+\left(\frac{N_{f}}{N_{T}}\right)^{c}
$$

we get

$$
\left.\left.\frac{\Delta \varepsilon}{\Delta \varepsilon_{T}}=\left(\frac{N_{f}}{N_{T}}\right)^{b}\left(\frac{\sigma_{f}^{\prime}-k \sigma_{0}}{\sigma_{f}^{\prime}}\right)^{\frac{N_{f}}{N_{T}}}\right)^{c} \vdots_{i} k^{\frac{b-c}{c}}\left(\frac{\sigma_{f}^{\prime}-k \sigma_{0}}{\sigma_{f}^{\prime}}\right)^{c / b}\right]
$$

where

${ }^{\Delta \varepsilon_{T}}$ is the transition strainrange for basic material under zero mean stress, and is given in general terms by Eq. $(A-3)$.

$\mathrm{N}_{\mathrm{T}}$ is the transition life for the basic material under zero mean stress, and is given in general terms by Eq. $(A-4)$.

$k$ is mean stress sensitivity of material, as discussed in report, equal to unity according to Morrow's formulation.

$k^{\prime} \quad$ is transition 1 ife sensitivity of material to mean stress, a function of mean stress.

$\sigma_{f}^{\prime}, \varepsilon_{f}^{\prime}, b$ and $c$ are the conventional material constants establishing the life relationship for the particular material.

Future experiments are required to establish the $k^{\prime}$ versus mean stress relationship. In the absence of special information, we can let $k^{\prime}=1$, which essentially assumes that the cyclic stress-strain curve is unaffected by mean stress.

It is possible to substitue into Eq. (B-4) the expression for ${ }^{\Delta \varepsilon} T$ and $N_{T}$ from Eqs. $(A-3)$ and $(A-4)$, resulting in

$\frac{\Delta \varepsilon}{2}=\left[\frac{\sigma_{f}^{\prime}-k \sigma_{0}}{E} ;\left(2 N_{f}\right)^{b}+\left[\frac{\left(\sigma_{f}^{\prime}-k \sigma_{o}\right.}{E}\right)^{c / b} k^{\left(\frac{b-c}{b}\right)}\right]\left(2 N_{f}\right)^{c}$ 
While Eq. (B-5) does not explicitly state how $k^{\prime}$ varies with $\sigma_{0}$ it is a general framework for future study of mean stress effects. It is clear that the life relation applies to both tensile and compressive mean stress, depending on the algebraic sign used for $\sigma_{0}$.

The life $\mathrm{N}_{f}$ with mean stress can be obtained from Eq. (B-5) by following the same inversion procedures outlined in Appendix A for the case of zero mean stress. 


\section{REFERENCES}

[1] H.J. Grover, An Observation Concerning the Cycle Ratio in Cumulative Damage, Fatigue of Aircraft Structures, ASTM STP 274, American Society for Testing and Materials, Philadelphia (1960) 120-124.

[2] S.S. Manson, International Journal of Fracture Mechanics, 2 (1966) 327-363.

[3] S.S. Manson, J.C. Freche, and C.R. Ensign, Application of a Double Linear Damage Rule to Cumulative Fatigue, Fatigue Crack Propagation, ASTM STP 415, American Society for Testing and Materials, Philadelphia (1967) 384-412.

[4] S.S. Manson, A.J. Nachtigall, and J.C. Freche, American Society for Testing and Materials, Proceedings, 61 (1961) 679-703.

[5] F.E. Richart, and N.M. Newmark, American Society for Testing and Materials, Proceedings, 48 (1948) 767-800.

[6] S.M. Marco and W.L. Starkey, American Society of Mechanical Engineers, Transactions, 76 (1954) 627-632.

[7] H.T. Corten and T.J. Dolan, Cumulative Fatigue Damage, International Conference on Fatique of Metals, Vol. 1, Institution of Mechanical Engineers, London (1956) Paper 2 of Session 3.

[8] S.S. Manson, Experimental Mechanics 5 (1965) 193-226.

[9] S.S. Manson and M.H. Hirschberg, Crack Initiation and Propagation in Notched Fatigue Specimens, International Conference on Fracture, 1st, Volume 1, T. Yokobori, et al., eds., Japanese Society for Strength and Fracture of Materials, Sendai, Japan (1966) 479-498.

[10] S.S. Manson and M.H. Hirschberg, Low Cycle Fatigue of Notched Specimens by Consideration of Crack Initiation and Propagation, NASA TN D-3746 (1967).

[11] L. Kaechele, Review and Analys is of Cumulative-Fatigue-Damage Theories, Memorandum RM-3650-PR, Rand Corporation, Santa Monica, California (1963).

[12] J. Walcher, D. Gray, and S.S. Manson, Aspects of Cumulative Fatigue Damage Analys is of Cold End Rotating Structures, AIAA Paper 79-1190 (1979).

[13] D. Webber and J.C. Levy, Cumulative Damage in Fatigue with Reference to Scatter of Results, Scientific and Technical Memorandum 15/58, Ministry of Supply, United Kingdom (1958).

[14] S.S. Manson, Journal of Fatigue of Engineering Materials and Structures, 1 (1979) 37-57.

[15] JoDean Morrow, Fatigue Properties in Metals, Section 3.2, Fatigue Design Handbook, Advances in Engineering, Volume 4, J.A. Graham, ed., Society of Automotive Engineers, Incorporated, Warrendale, (1968) 21-29.

[16] R.W. Landgraf, Cumulative Fatigue Damage Under Complex Strain Histories, Cyclic Stress-Strain Behavior-Analysis, Experimentation, and Prediction, ASTM STP 519, American Society for Testing and Materials, philadelphia (1973) 213-228. 
TABLE I. APPLICATION OF THE DOUBLE LINEAR DAMAGE RULE TO A COMPLEX MISSION CYCLE:

\begin{tabular}{|c|c|c|c|c|c|c|c|c|}
\hline \multirow[t]{2}{*}{ EVENT } & \multicolumn{2}{|c|}{$\begin{array}{l}\text { LOADING } \\
\text { CONDITIONS } \\
\end{array}$} & \multirow{2}{*}{$\begin{array}{l}\text { NO. CYCLES } \\
\text { PER MISSION } \\
n\end{array}$} & \multirow{2}{*}{$\begin{array}{l}\text { CYCLES TO } \\
\text { FAILURE } \\
\mathrm{N}_{f_{(B-1)}} \\
\text { Eq. }\end{array}$} & \multirow{2}{*}{$\begin{array}{c}\text { CYCLES TO } \\
\text { END OF PHASE I } \\
N^{\mathrm{I}} \\
(\mathrm{Eq} \cdot 25) \\
\end{array}$} & \multirow{2}{*}{ 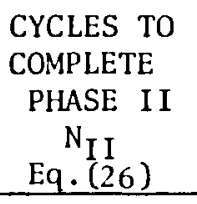 } & \multirow{2}{*}{$\frac{\mathrm{n}}{\mathrm{N}_{\mathrm{I}}}$} & \multirow{2}{*}{$\frac{n}{N_{I I}}$} \\
\hline & $\begin{array}{l}\Delta \varepsilon \\
\text { in } / \text { in }\end{array}$ & $\begin{array}{c}\sigma_{0}, \\
\mathrm{MPa}\end{array}$ & & & & & & \\
\hline 1 & 0.00254 & 695 & 4 & 37180 & 23643 & 13537 & $1.692 \times 10^{-4}$ & $2.955 \times 10^{-4}$ \\
\hline 2 & 0.00791 & 394 & 2 & 7200 & 2474 & 4726 & 8.084 & 4.232 \\
\hline 3 & 0.00735 & 359 & 1 & 13650 & 6354 & 7296 & 1.574 & 1.371 \\
\hline 4 & 0.01017 & 268 & 6 & 5550 & 1632 & 3918 & 36.770 & 15.310 \\
\hline 5 & 0.00396 & 616 & 3 & 17400 & 8873 & 8527 & 3.381 & 3.518 \\
\hline 6 & 0.00198 & 727 & 2 & 64000 & 45518 & 18482 & 0.439 & 1.082 \\
\hline 7 & 0.00848 & 172 & 1 & 33000 & 20382 & 12618 & 0.491 & 0.793 \\
\hline 8 & 0.01564 & 62 & 2 & 2500 & 390 & 2110 & 51.280 & 9.479 \\
\hline 9 & 0.01045 & 3 & 1 & 31325 & 19092 & 12233 & 0.524 & 0.817 \\
\hline 10 & 0.00932 & 66 & 1 & 42540 & 27897 & 14643 & 0.359 & 0.683 \\
\hline 11 & 0.01074 & 145 & 1 & 9390 & 3706 & 5684 & 2.698 & 1.759 \\
\hline 12 & 0.01271 & 127 & 1 & 4440 & 1122 & 3318 & 8.913 & 3.014 \\
\hline 13 & 0.01158 & 188 & 1 & 4900 & 1327 & 3573 & 7.536 & 2.799 \\
\hline 14 & 0.00452 & 557 & 2 & 20605 & 11124 & 9481 & 1.798 & 2.110 \\
\hline \multicolumn{7}{|c|}{ TOTALS } & $125.539 \times 10^{-4}$ & $49.922 \times 10^{-4}$ \\
\hline \multicolumn{9}{|c|}{$\begin{array}{l}\text { MISSIONS TO COMPLETE PHASE I DAMAGE }=1 / .0126=79 \\
\text { MISSIONS TO COMPLETE PHASE II DAMAGE }=1 / .005=200\end{array}$} \\
\hline
\end{tabular}


TABLE II. APPLICATION OF CUMULATIVE FATIGUE DAMAGE RULES TO THREE STEP LEVEL TESTS OF WEBBER AND LEVY (REF. 13) FOR D.T.D. 683 ALUMINUM.

\begin{tabular}{|c|c|c|c|c|c|c|c|c|c|c|c|c|}
\hline (1) & $(2)$ & (3) & (4) & (5) & (6) & (7) & (8) & (9) & $(10)$ & (11) & $(12)$ & $(13)$ \\
\hline \multirow{3}{*}{$\begin{array}{c}\text { TEST } \\
\text { No. }\end{array}$} & \multirow{2}{*}{\multicolumn{3}{|c|}{$\begin{array}{l}\text { TEST CONDITION (a) } \\
\% \text { of } 9500 \text { cycle block } \\
\text { at each life level }\end{array}$}} & \multicolumn{6}{|c|}{ CYCLES TO FAILURE IN $1000 \mathrm{~s}$} & \multicolumn{3}{|c|}{ RATIO, PREDICTED/EXPERIMENTAL } \\
\hline & & & & \multirow[b]{2}{*}{ Exp. } & \multirow[b]{2}{*}{ LDR } & \multirow{2}{*}{$\mathrm{DLDR}^{(\mathrm{b})}$} & \multirow{2}{*}{$\operatorname{DLDR}^{(\mathrm{c})}$} & \multirow{2}{*}{$\begin{array}{l}\text { Damage } \\
\text { Curve }\end{array}$} & \multirow{2}{*}{$\begin{array}{l}\text { Damage }^{(e)} \\
\text { Curve }\end{array}$} & \multirow[b]{2}{*}{ LDR } & \multirow{2}{*}{$\mathrm{DLDR}^{(\mathrm{b})}$} & \multirow{2}{*}{$\begin{array}{l}\text { Damage } \\
\text { Curve }\end{array}$} \\
\hline & $\mathrm{n}_{1}$ & $\mathrm{n}_{2}$ & $\mathrm{n}_{3}$ & & & & & & & & & \\
\hline 1 & 1 & 63 & 36 & 437 & 575 & 509 & 510 & 494 & 513 & 1.32 & 1.17 & 1.13 \\
\hline 2 & 1 & 42 & 57 & 871 & 801 & 672 & 668 & 656 & 694 & 0.92 & 0.77 & 0.75 \\
\hline 3 & 1 & 15 & 84 & 741 & 1624 & 1151 & 1108 & 1178 & 1292 & 2.19 & 1.55 & 1.59 \\
\hline 4 & 4.2 & 63 & 32.8 & 363 & 425 & 356 & 345 & 352 & 380 & 1.17 & 0.98 & 0.97 \\
\hline 5 & 4.2 & 42 & 53.8 & 372 & 537 & 439 & 415 & 437 & 456 & 1.44 & 1.18 & 1.17 \\
\hline 6 & 4.2 & 15 & 80.8 & 550 & 813 & 637 & 572 & 646 & 693 & 1.48 & 1.16 & 1.17 \\
\hline 7 & 10 & 63 & 27 & 275 & 288 & 248 & 235 & 238 & 257 & 1.05 & 0.90 & 0.86 \\
\hline 8 & 10 & 42 & 48 & 282 & 336 & 289 & 271 & 289 & 299 & 1.19 & 1.03 & 1.03 \\
\hline 9 & 10 & 15 & 75 & 269 & 427 & 371 & 340 & 371 & 385 & 1.59 & 1.38 & 1.38 \\
\hline & & & & & & & & & verages & 1.37 & 1. 12 & 1.12 \\
\hline
\end{tabular}
(a) $\mathrm{N}_{1}=51,900$
$N_{2}=414,140$
$N_{3}=13,800,000$
(b) Using $\mathrm{N}_{1}$ and $\mathrm{N}_{3}$ for calculation of kneepoint
(c) Using $\mathrm{N}_{1}^{1}$ and $\mathrm{N}_{2}^{3}$ for calculation of kneepoint
(d) Using exponent of 0.40
(e) Using exponent of 0.33 


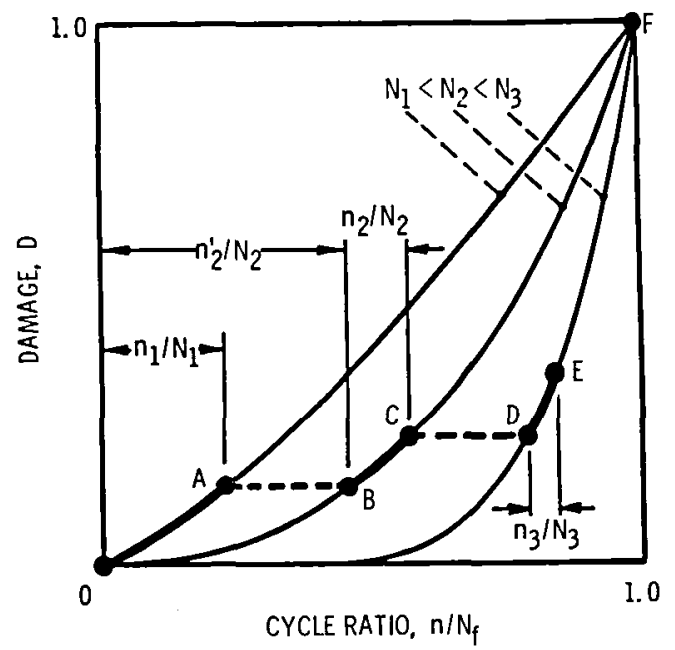

Figure l. - Schematic of damage curve concept of summing cumulative damage in complex loading.

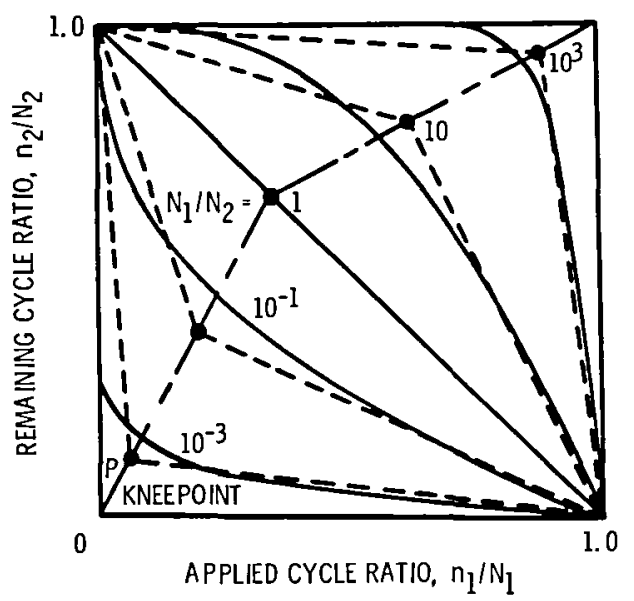

Figure 2. - Cycle ratio relationship for two level test as deduced from damage curve, and replacement of damage curves by two straight line segments. 


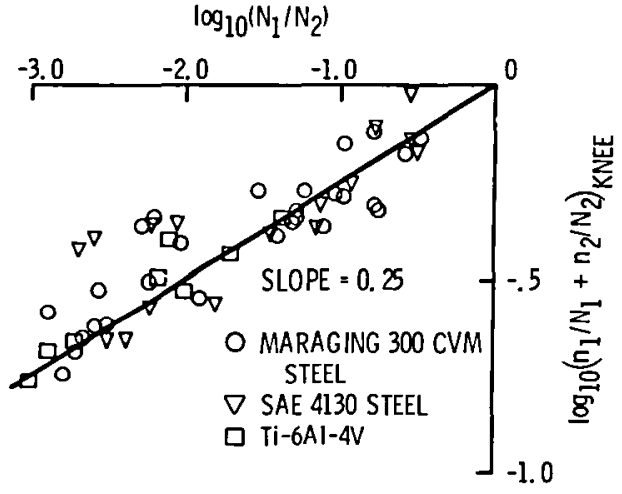

Figure 3. - Determination of exponent in

Eq. (14) used in calculating the kneepoint for the double linear damage rule.

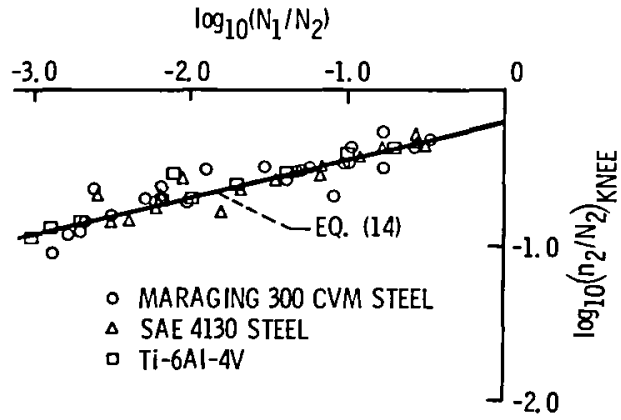

Figure 4. - Determination of coefficient $B$ in Eq. (14) used in calculating the kneepoint for the double linear damage rule. 
- MARAGING 300 CVM STEEL

DOMAGE CURVE ANALYSIS
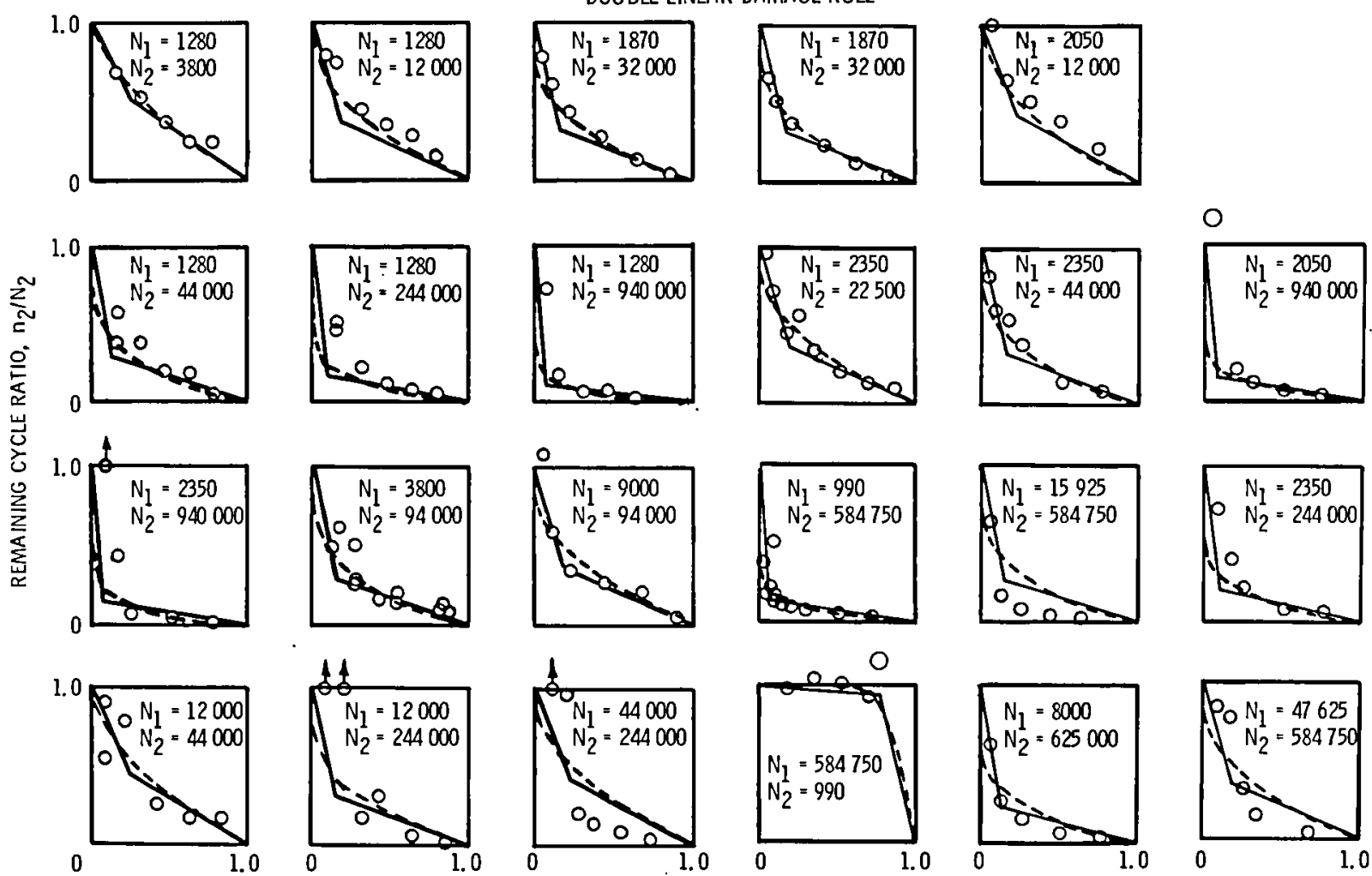

Figure 5. - Two load level test results for maraging 300 CVM steel showing comparison with predictions by the damage curve approach and the double linear damage rule. Data from Ref. (3) and previously unpublished NASA results. 


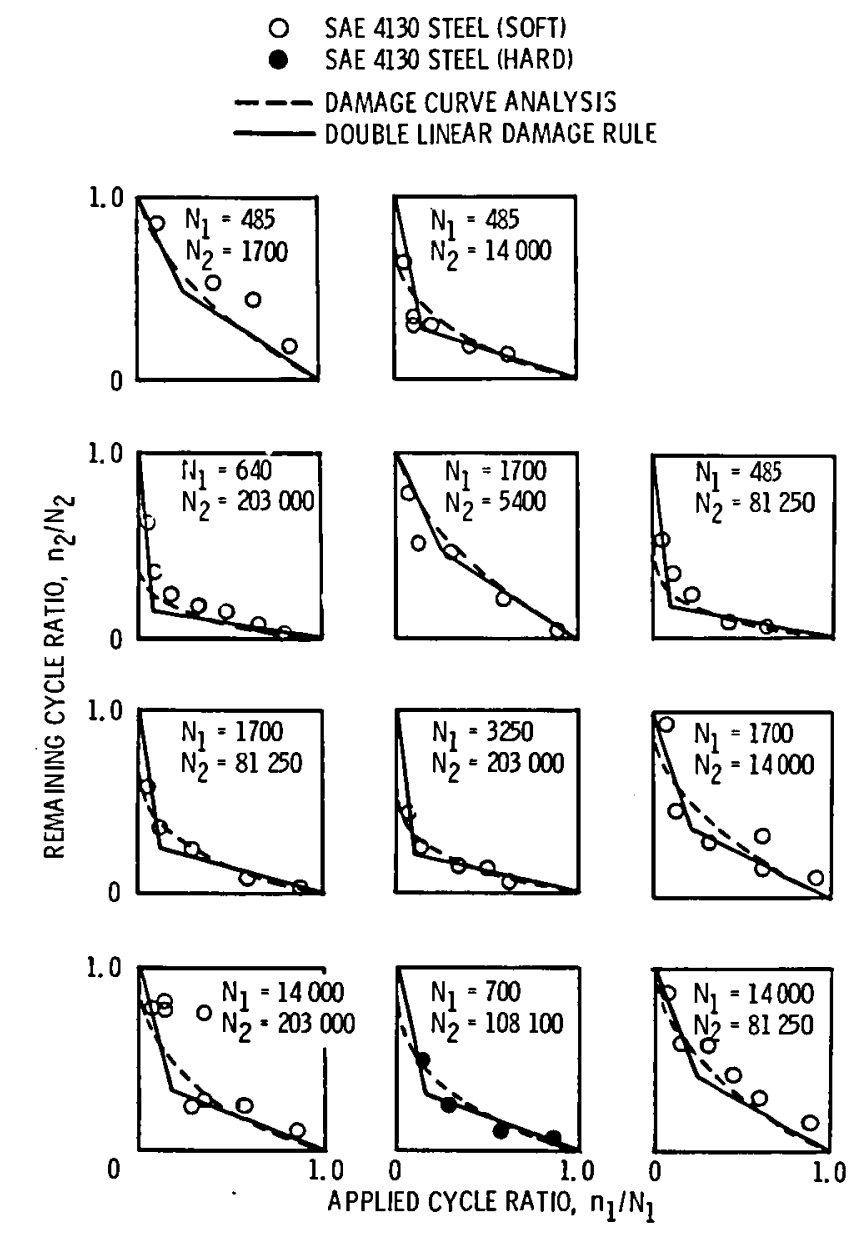

Figure 6. - Two load level test results for SAE 4130 steel showing comparison with predictions by the damage curve approach and the double linear damage rule. Data from Ref. (3).

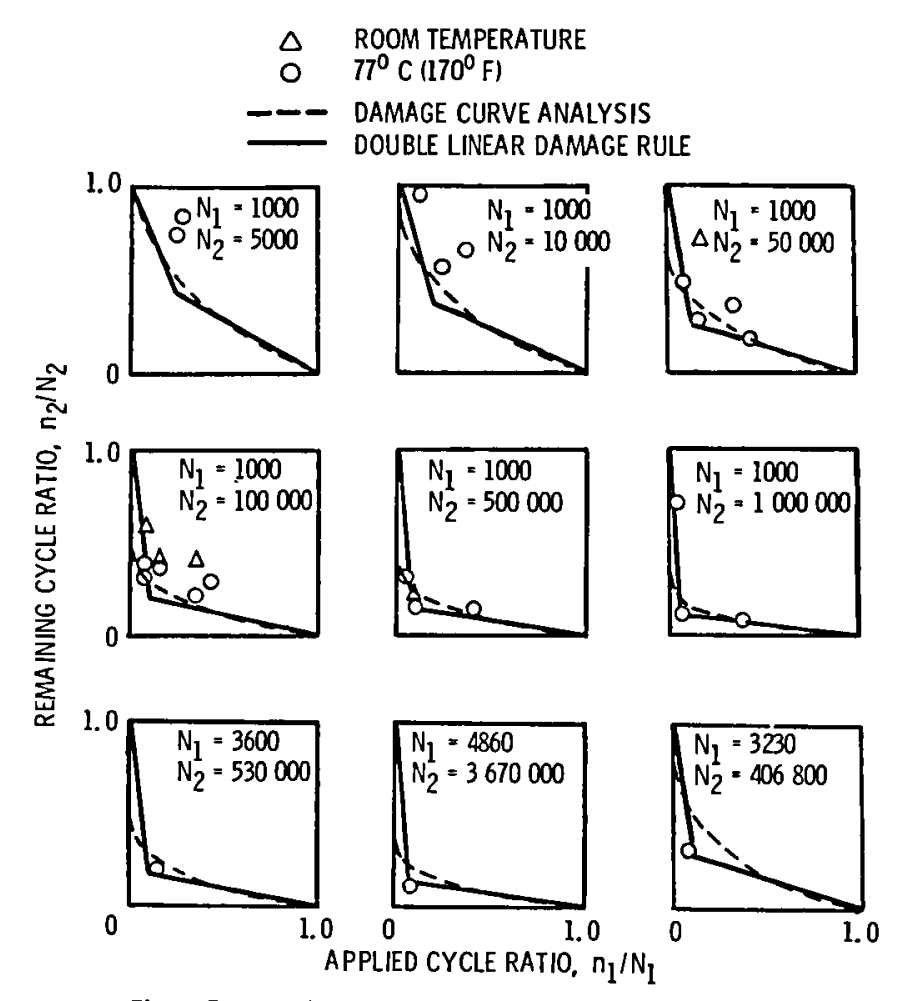

Figure 7. - Two load level test results for Ti-6Al-4V with and without mean stresses showing comparison with predictions by the damage curve approach and the double linear damage rule. Data
from Ref. (12). 
- $\quad$ LOW TO HIGH STRESS

- HIGH TO LOW STRESS

DAMAGE CURVE ANALYSIS

DOUBLE LINEAR DAMAGE RULE

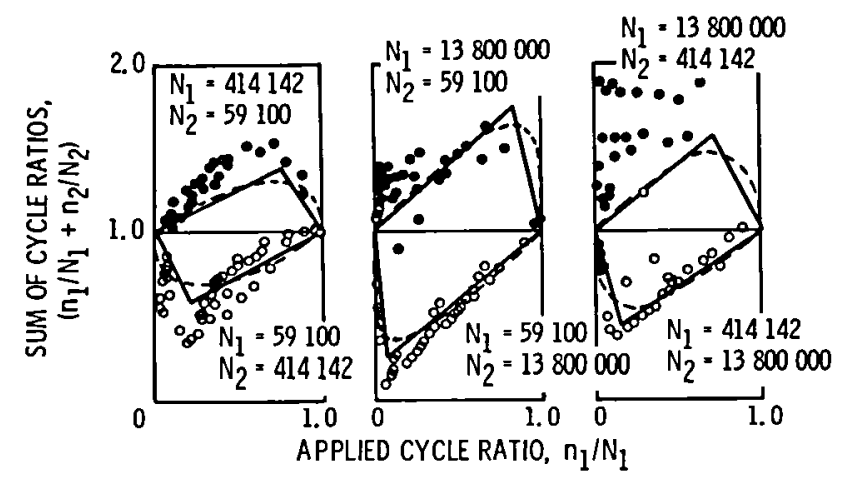

Figure 8. - Two load level test results for British aluminum alloy D. T.D. 683 showing comparison with the damage curve analysis and the double linear damage rule. Data from Ref. (13).

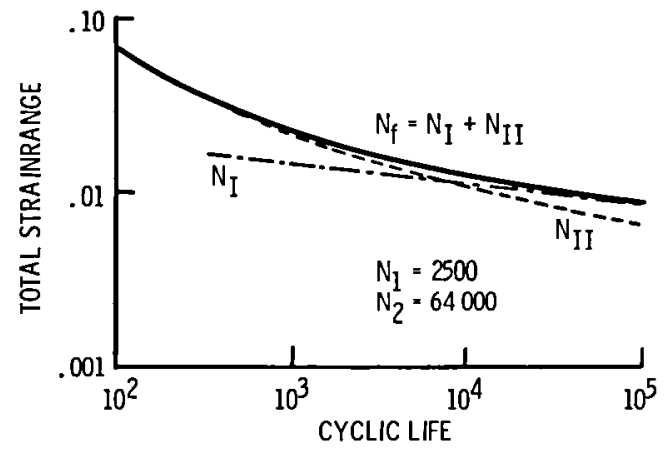

Figure 9. - Low cycle fatigue life relations for Phase I, Phase II, and total life for Ti-6AI- $4 \mathrm{~V}$ at $77^{\circ} \mathrm{C}\left(170^{\circ} \mathrm{F}\right)$. Zero mean stress condition.

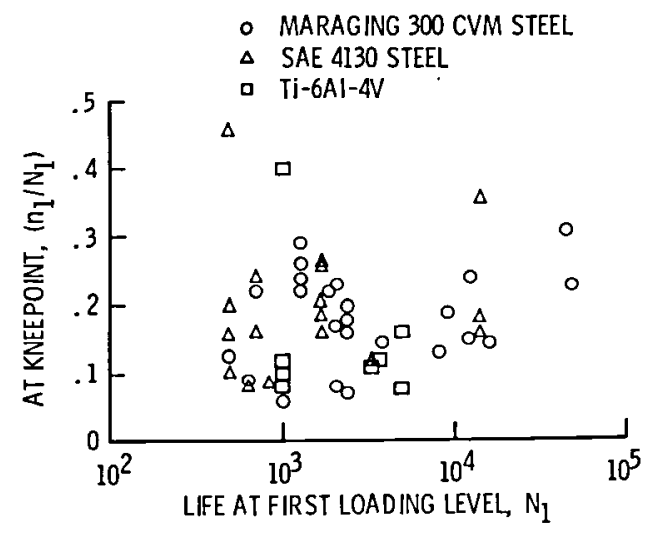

Figure 10. - Lack of correlation between kneepoint coordinate and the concept of a discrete crack initiation event. 


\begin{tabular}{|c|c|c|c|c|}
\hline $\begin{array}{l}\text { 1. Report No. } \\
\text { NASA TM-81517 }\end{array}$ & \multicolumn{2}{|c|}{ 2. Government Accession No. } & \multicolumn{2}{|c|}{ 3. Recipient's Catalog No. } \\
\hline \multirow{2}{*}{\multicolumn{3}{|c|}{$\begin{array}{l}\text { 4. Title and Subtitle } \\
\text { PRAC TICAL IMP LEMENTATION OF THE DOUBLE LINEAR } \\
\text { DAMAGE RULE AND DAMAGE CURVE APPROACH FOR } \\
\text { TREATING CUMULATIVE FA TIGUE DAMAGE }\end{array}$}} & \multicolumn{2}{|l|}{$\begin{array}{l}\text { 5. Report Date } \\
\text { April } 1980\end{array}$} \\
\hline & & & \multicolumn{2}{|c|}{ 6. Performing Organization Code } \\
\hline \multirow{2}{*}{\multicolumn{2}{|c|}{$\begin{array}{l}\text { 7. Author(s) } \\
\text { S. S. Manson and G. R. Halford }\end{array}$}} & & \multicolumn{2}{|c|}{$\begin{array}{l}\text { 8. Performing Organization Report No. } \\
\text { E-387 }\end{array}$} \\
\hline & & & \multirow{2}{*}{\multicolumn{2}{|c|}{ 10. Work Unit No. }} \\
\hline \multirow{3}{*}{\multicolumn{3}{|c|}{$\begin{array}{l}\text { 9. Performing Organization Name and Address } \\
\text { National Aeronautics and Space Administration } \\
\text { Lewis Research Center } \\
\text { Cleveland, Ohio } 44135\end{array}$}} & & \\
\hline & & & \multicolumn{2}{|c|}{ 11. Contract or Grant No. } \\
\hline & & & \multirow{2}{*}{\multicolumn{2}{|c|}{$\begin{array}{l}\text { 13. Type of Report and Period Covered } \\
\text { Technical Memorandum }\end{array}$}} \\
\hline \multirow{2}{*}{\multicolumn{3}{|c|}{$\begin{array}{l}\text { 12. Sponsoring Agency Name and Address } \\
\text { National Aeronautics and Space Administration } \\
\text { Washington, D. C. } 20546\end{array}$}} & & \\
\hline & & & \multicolumn{2}{|c|}{ 14. Sponsoring Agency Code } \\
\hline \multicolumn{5}{|c|}{$\begin{array}{l}\text { 15. Supplementary Notes } \\
\text { S. S. Manson, Case Western Reserve University, Cleveland, Ohio } 44106 \text {; G. R. Halford, } \\
\text { NASA Lewis Research Center. }\end{array}$} \\
\hline \multicolumn{5}{|c|}{$\begin{array}{l}\text { 16. Abstract } \\
\text { Simple procedures are presented for treating cumulative fatigue damage under complex loading } \\
\text { history using either the Damage Curve concept or the Double Linear Damage Rule. A single } \\
\text { equation is provided for use with the Damage Curve approach; each loading event providing a } \\
\text { fraction of damage until failure is presumed to occur when the damage sum becomes unity. } \\
\text { For the Double Linear Damage Rule, analytical expressions are provided for determining the } \\
\text { two phases of life. The procedure involves two steps, each similar to the conventional appli- } \\
\text { cation of the commonly used Linear Damage Rule. When the sum of cycle ratios based on } \\
\text { Phase I lives reaches unity, Phase I is presumed complete, and further loadings are summed } \\
\text { as cycle ratios based on Phase II lives. When the Phase II sum reaches unity, failure is pre- } \\
\text { sumed to occur. No other physical properties or material constants than those normally used } \\
\text { in a conventional Linear Damage Rule analysis are required for application of either of the two } \\
\text { cumulative damage methods described. Illustrations and comparisons of both methods are } \\
\text { discussed. }\end{array}$} \\
\hline \multicolumn{2}{|c|}{$\begin{array}{l}\text { 17. Key Words (Suggested by Author(s)) } \\
\text { Metal fatigue; Crack initiation; Crack } \\
\text { propagation; Cumulative damage; Linear } \\
\text { damage; Miner Rule; Mean stress; } \\
\text { Life prediction }\end{array}$} & \multicolumn{3}{|c|}{$\begin{array}{l}\text { 18. Distribution Statement } \\
\text { Unclassified - unlimited } \\
\text { STAR Category } 39\end{array}$} \\
\hline $\begin{array}{r}\text { 19. Security Classif. (of this report) } \\
\text { Unclassified }\end{array}$ & 20. Security & $\begin{array}{l}\text { f this pagel } \\
\text { lassified }\end{array}$ & 21. No. of Pages & 22. Price \\
\hline
\end{tabular}

${ }^{*}$ For sale by the National Technical Information Service, Springfield, Virginia 22161 


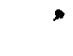

, 
National Aeronautics and Space Administration
SPECIAL FOURTH CLASS MAIL BOOK
Washington, D.C.

20546

Official Business

Penalty for Private Use, $\$ 300$
Postage and Fees Paid Space Administration NASA 451 National Aeronautics and 